\title{
REVIEW
}

\section{Estrogen biosynthesis in endometriosis: molecular basis and clinical relevance}

\section{S E Bulun ${ }^{1}, \mathbf{K}$ M Zeitoun ${ }^{2}, \mathbf{K}$ Takayama $^{3}$ and $\mathbf{H ~ S a s a n o ~}^{3}$}

${ }^{1}$ Departments of Obstetrics and Gynecology and Molecular Genetics, University of Illinois at Chicago, 820 S. Wood St. M/C 808, Illinois 60612, USA

${ }^{2}$ Department of Obstetrics and Gynecology, Columbia University College of Physicians and Surgeons, 622 W. 168th St., New York, New York 10032-3702, USA

${ }^{3}$ Departments of Pathology and Obstetrics and Gynecology, Tohoku University School of Medicine, 2-1 Seiryo Machi, Sendai-Shi 980, Japan

(Requests for offprints should be addressed to S E Bulun; Email: sbulun@uic.edu)

\begin{abstract}
Conversion of $\mathrm{C}_{19}$ steroids to estrogens is catalyzed by aromatase in human ovary, placenta and extraglandular tissues such as adipose tissue, skin and the brain. Aromatase activity is not detectable in normal endometrium. In contrast, aromatase is expressed aberrantly in endometriosis and is stimulated by prostaglandin $\mathrm{E}_{2}\left(\mathrm{PGE}_{2}\right)$. This results in local production of estrogen, which induces $\mathrm{PGE}_{2}$ formation and establishes a positive feedback cycle. Another abnormality in endometriosis, i.e.
\end{abstract}

deficient hydroxysteroid dehydrogenase (17 $\beta$-HSD) type 2 expression, impairs the inactivation of estradiol to estrone. These molecular aberrations collectively favor accumulation of increasing quantities of estradiol and $\mathrm{PGE}_{2}$ in endometriosis. The clinical relevance of these findings was exemplified by the successful treatment of an unusually aggressive case of postmenopausal endometriosis using an aromatase inhibitor.

Fournal of Molecular Endocrinology (2000) 25, 35-42

\section{INTRODUCTION}

Endometriosis is a chronic disease manifested by pelvic pain and infertility and defined as the presence of endometrial glands and stroma within the pelvic peritoneum and other extra-uterine sites. It is estimated to affect $2-10 \%$ of women in the reproductive age group (Vessey et al. 1993, Kjerulff et al. 1996). Endometriosis is viewed to be a polygenically inherited disease of complex multifactorial etiology (Olive \& Schwartz 1993). Sampson's theory of transplantation of endometrial tissue on the pelvic peritoneum via retrograde menstruation is the most widely accepted explanation for the development of pelvic endometriosis because of convincing circumstantial and experimental evidence (Sampson 1927). Since retrograde menstruation is observed in almost all cycling women, endometriosis is postulated to develop as a result of the coexistence of a defect in clearance of the menstrual efflux from pelvic peritoneal surfaces, possibly involving the immune system (Halme et al. 1988). Alternatively, intrinsic molecular aberrations in pelvic endometriotic implants were proposed to contribute significantly to development of endometriosis. Aberrant expression of aromatase, certain cytokines and tissue metalloproteinases, deficiency of $17 \beta$-hydroxysteroid dehydrogenase (17 $\beta$-HSD) type 2 and resistance to the protective action of progesterone are some of these molecular abnormalities (Khorram et al. 1993, Sharpe-Timms et al.1995, Noble et al. 1996, Osteen et al. 1996, Bruner et al. 1997, Zeitoun et al. 1998, 1999). Since endometriosis is an estrogen-dependent disorder, aromatase expression and 17 $\beta$-HSD type 2 deficiency are of paramount importance in the pathophysiology of endometriosis. In this article, aberrant mechanisms of estrogen biosynthesis and metabolism in women with endometriosis are reviewed, with emphasis on identifying targets for new treatment strategies. 


\section{DISCUSSION}

\section{Estrogen biosynthesis and metabolism in humans}

The conversion of androstenedione and testosterone to estrone and estradiol is catalyzed by aromatase, which is expressed in a number of human tissues and cells such as ovarian granulosa cells, placental syncytiotrophoblast, adipose tissue and skin fibroblasts, and the brain. In the reproductive-age woman, the ovary is the most important site of estrogen biosynthesis, and this takes place in a cyclic fashion. Upon binding of follicle-stimulating hormone $(\mathrm{FSH})$ to its $\mathrm{G}$-protein-coupled receptor in the granulosa cell membrane, intracellular cAMP levels rise and enhance binding of two critical transcription factors, i.e. steroidogenic factor-1 (SF-1) and cAMP response element binding protein (CREB), to the classically located proximal promoter II of the aromatase gene (Michael et al. 1995, 1997). This, in turn, activates aromatase expression and consequently estrogen secretion from the pre-ovulatory follicle (Simpson et al. 1994, Michael et al. 1995).

On the other hand, in postmenopausal women, estrogen formation takes place in extra-ovarian tissues such as the adipose tissue and skin (MacDonald et al. 1967, 1978, Ackerman et al. 1981) (Fig. 1). In contrast to cAMP regulation of aromatase expression in the ovary, this is controlled primarily by cytokines (IL-6, IL-11, TNF $\alpha$ ) and glucocorticoids via the alternative use of promoter I.4 in adipose tissue and skin fibroblasts (Simpson et al. 1994). The major substrate for aromatase in adipose tissue and skin is androstenedione of adrenal origin. In postmenopausal women, approximately $2 \%$ of circulating androstenedione is converted to estrone, which is further converted to estradiol in these extra-ovarian tissues. This may give rise to significant serum levels of estradiol capable of causing endometrial hyperplasia or even carcinoma (MacDonald et al. 1967, 1978).

\section{Aromatase expression in Müllerian-derived tissues}

Müllerian tissues are known targets of estrogen action. Until recently, estrogen action has been classically viewed to occur only via an 'endocrine' mechanism: in other words, it was thought that only circulating estradiol, whether secreted by the ovary or formed in the adipose tissue, could exert an estrogenic effect after delivery to target tissues via the bloodstream. Studies on aromatase expression in breast cancer demonstrated that paracrine

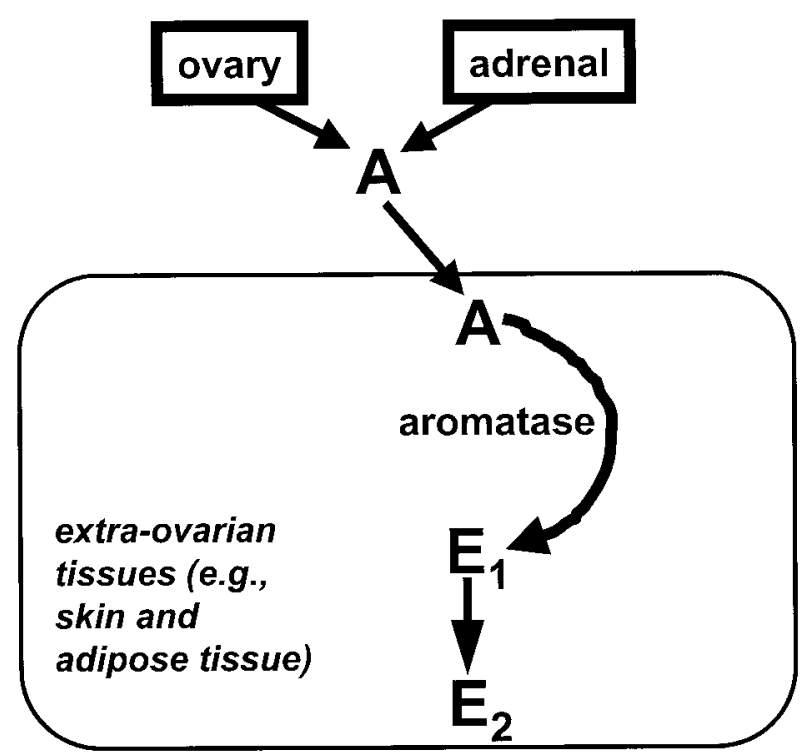

FIGURE 1. Extra-ovarian estrogen formation in women. Estradiol $\left(\mathrm{E}_{2}\right)$ in women is either directly secreted by the ovary or produced in extra-ovarian sites (adipose tissue and skin). The principal substrate for extraovarian aromatase activity in women is androstenedione (A) of adrenal and ovarian origins. Androstenedione is converted by aromatase to estrone $\left(E_{1}\right)$ in adipose tissue and skin fibroblasts. Estrone is further converted to $\mathrm{E}_{2}$ by $17 \beta$-HSD type 1 activity in these peripheral tissues. Thus, extra-ovarian aromatization is the major source for circulating $\mathrm{E}_{2}$ in the postmenopausal period or during ovarian suppression.

mechanisms play an important role in estrogen action in this tissue (Bulun et al. 1993a). Estrogen produced by aromatase activity in breast adipose tissue fibroblasts was demonstrated to promote the growth of adjacent malignant breast epithelial cells (Yue et al. 1998). Finally, we demonstrated an 'intracrine' effect of estrogen in uterine leiomyomas and endometriosis: estrogen produced by aromatase activity in the cytoplasm of leiomyoma smooth muscle cells or endometriotic stromal cells can exert its effects by readily binding to its nuclear receptor within the same cell (Bulun et al. 1994, Noble et al. 1996, 1997). Disease-free endometrium and myometrium, on the other hand, lack aromatase expression (Bulun et al. 1993b, Noble et al. 1997).

\section{The significance of aromatase expression in endometriosis}

Among estrogen-responsive pelvic disorders, aromatase expression was studied in greatest detail in endometriosis (Bulun et al. 1993b, Noble et al. 1996, 1997, Zeitoun et al. 1999). Firstly, extremely high 
levels of aromatase mRNA were found in extraovarian endometriotic implants and endometriomas. Secondly, endometriosis-derived stromal cells in culture incubated with a cAMP analog displayed extraordinarily high levels of aromatase activity comparable to that in placental syncytiotrophoblast (Noble et al. 1997). These exciting findings led us to test a battery of growth factors, cytokines and other substances that might induce aromatase activity via a cAMP-dependent pathway in endometriosis. Prostaglandin $\mathrm{E}_{2}\left(\mathrm{PGE}_{2}\right)$ was found to be the most potent known inducer of aromatase activity in endometriotic stromal cells (Noble et al. 1997). In fact, this $\mathrm{PGE}_{2}$ effect was found to be mediated via the cAMP-inducing $\mathrm{EP}_{2}$ receptor subtype. Moreover, estrogen was reported to increase $\mathrm{PGE}_{2}$ formation by stimulating cyclo-oxygenase type 2 (COX-2) enzyme in endometrial stromal cells in culture (Huang et al. 1996). Thus, a positive feedback loop for continuous local productions of estrogen and PGs is established, favoring the proliferative and inflammatory characteristics of endometriosis (Fig. 2). Additionally, aromatase mRNA was also detected in the eutopic endometrial samples of women with moderate to severe endometriosis (but not in those of disease-free women) albeit in much smaller quantities compared with endometriotic implants (Noble et al. 1996). This may be suggestive of a genetic defect in women with endometriosis, which is manifested by this subtle finding in the eutopic endometrium. We propose that when defective endometrium with low levels of aberrant aromatase expression reaches the pelvic peritoneum by retrograde menstruation, it causes an inflammatory reaction that exponentially increases local aromatase activity, i.e. estrogen formation, induced directly or indirectly by PGs and cytokines (Noble et al. 1997). It would be rather naive to propose that aberrant aromatase expression is the only important molecular mechanism in the development and growth of pelvic endometriosis. There may be many other molecular mechanisms that favor the development of endometriosis: abnormal expression of proteinase type enzymes that remodel tissues or their inhibitors (matrix metalloproteinases, tissue inhibitor of metalloproteinase-1), certain cytokines (IL-6, RANTES) and growth factors (EGF) represent some of mechanisms (Khorram et al. 1993, Sharpe-Timms et al. 1995, Osteen et al. 1996, Bruner et al. 1997). Alternatively, a defective immune system that fails to clear peritoneal surfaces of the retrograde menstrual efflux has been proposed in the development of endometriosis (Halme et al. 1988, Hill 1992). The development of endometriosis in an individual woman probably requires the coexistence of a threshold number of

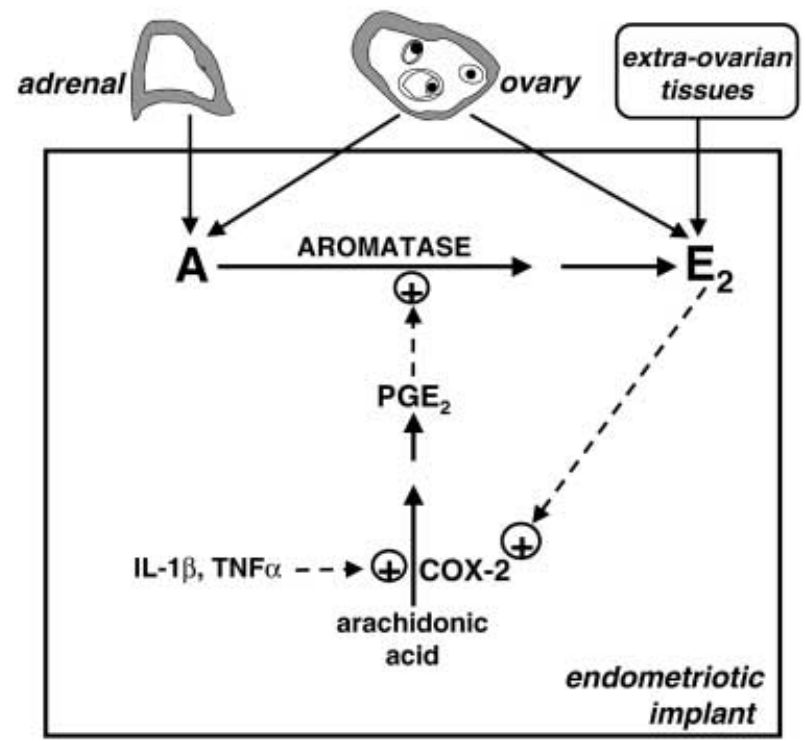

FIGURE 2. Origin of estrogen in endometriotic lesions: estradiol $\left(\mathrm{E}_{2}\right)$ that affects an endometriotic lesion arises from several body sites. In an ovulatory woman, $\mathrm{E}_{2}$ is secreted directly from the ovary in a cyclic fashion. In the early follicular phase and after menopause, extraovarian tissues (adipose and skin) are the most important sources to account for the circulating $\mathrm{E}_{2}$. Estradiol is also produced locally in the endometriotic implant itself in both ovulatory and postmenopausal women. The most important precursor, androstenedione (A) of adrenal and ovarian origins, becomes converted to estrone $\left(E_{1}\right)$ that is in turn reduced to $E_{2}$ in these tissues and endometriotic implants. We demonstrated significant levels of $17 \beta$-hydroxysteroid dehydrogenase type 1 expression in endometriosis, which catalyzes the conversion of $\mathrm{E}_{1}$ to $\mathrm{E}_{2}$ (Zeitoun et al. 1998). Estradiol and cytokines (IL-l $\alpha, \mathrm{TNF} \beta$ ), which are increased in endometriosis, induce cyclo-oxygenase-2 (COX-2) giving rise to elevated concentrations of $\mathrm{PGE}_{2}$ in this tissue (Huang et al.). $\mathrm{PGE}_{2}$ in turn, is the most potent known stimulator of aromatase in endometriotic stromal cells (Noble et al. 1997). This establishes a positive feedback loop in favor of continuous estrogen formation in endometriosis.

these aberrations. Nonetheless, aberrant aromatase expression is clinically relevant, since aromatase inhibitors suppress postmenopausal endometriosis (Takayama et al. 1998).

\section{Regulation of aromatase expression in endometriotic stromal cells}

As emphasized earlier, $\mathrm{PGE}_{2}$ was found to be the most potent known inducer of aromatase activity by increasing cAMP levels via cell surface $\mathrm{EP}_{2}$ receptors in endometriotic stromal cells (Noble 


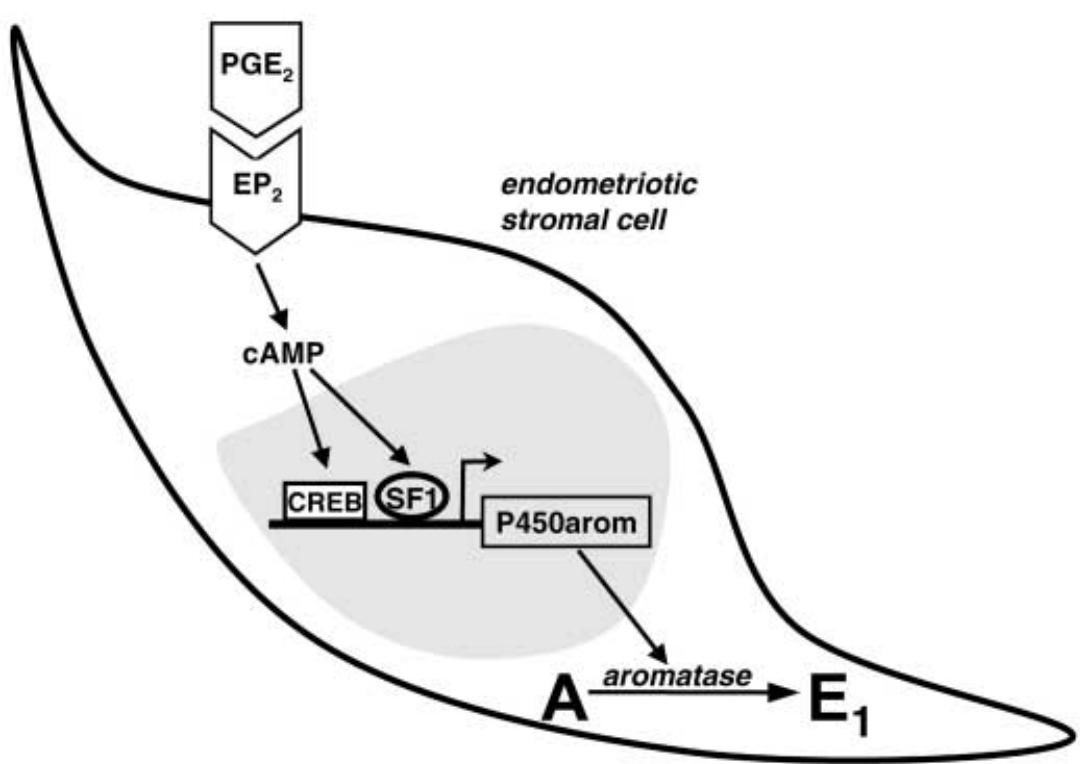

FIGURE 3. Proposed mechanism of regulation of aromatase (P450arom) expression by SF-1 and CREB in endometriosis. Upon binding of $\mathrm{PGE}_{2}$ to its cell surface $\mathrm{EP}_{2}$ receptor, intracellular cAMP levels increase. This gives rise to binding of cAMP response element binding protein (CREB) and SF-1 to specific motifs upstream of aromatase promoter II. The stimulatory type transcription factor SF-1 binds as a monomer to a nuclear receptor half-site with a higher affinity compared with that of the inhibitory factor COUP-TF (not shown in the figure), which binds to the same site relatively loosely as a dimer. SF-1 then synergizes with CREB (bound to upstream CRE) and possibly other factors to activate transcription of the P450arom gene in response to cAMP (Zeitoun et al. 1999).

et al. 1997). On the other hand, neither cAMP analogs nor $\mathrm{PGE}_{2}$ was capable of stimulating any detectable aromatase activity in eutopic endometrial stromal cells in culture. The obvious question became: what are the molecular differences that give rise to aromatase expression in endometriosis and its inhibition in eutopic endometrium? To address this, we first determined that the cAMP-inducible promoter II was used for in vivo aromatase expression in endometriotic tissue (Zeitoun et al. 1999). Then, a stimulatory transcription factor, SF-1, and an inhibitory factor, chicken ovalbumin upstream promoter transcription factor (COUP$\mathrm{TF}$ ), were found to compete for the same binding site in aromatase promoter II. COUP-TF was ubiquitously expressed in both eutopic endometrium and endometriosis, whereas SF-1 was expressed, specifically in endometriosis but not in eutopic endometrium, and binds to aromatase promoter more avidly than COUP-TF (Zeitoun et al. 1999). Thus, SF-1 and other transcription factors (e.g. CREB) activate transcription in endometriosis, whereas COUP-TF, which occupies the same DNA site in eutopic endometrium, inhibits this process (Zeitoun et al. 1999) (Fig. 3). In summary, one of the molecular alterations leading to local aromatase expression in endometriosis but not in normal endometrium is the aberrant production of SF-1 in endometriotic stromal cells, which overcomes the protective inhibition maintained normally by COUP-TF in the eutopic endometrium.

\section{Interconversions of estrone and estradiol in endometriosis}

The primary substrate for aromatase activity in endometriosis is androstenedione of adrenal and ovarian origins in premenopausal women. The major product of aromatase activity in endometriosis, namely estrone, is only weakly estrogenic and must be converted to the potent estrogen estradiol to exert a full estrogenic effect. We demonstrated that the enzyme $17 \beta-\mathrm{HSD}$ type 1 , which catalyzes the conversion of estrone to estradiol, is expressed in endometriosis (Andersson \& Moghrabi 1997, Zeitoun et al. 1998). In contrast, the enzyme $17 \beta$-HSD type 2 (encoded by a separate gene) 

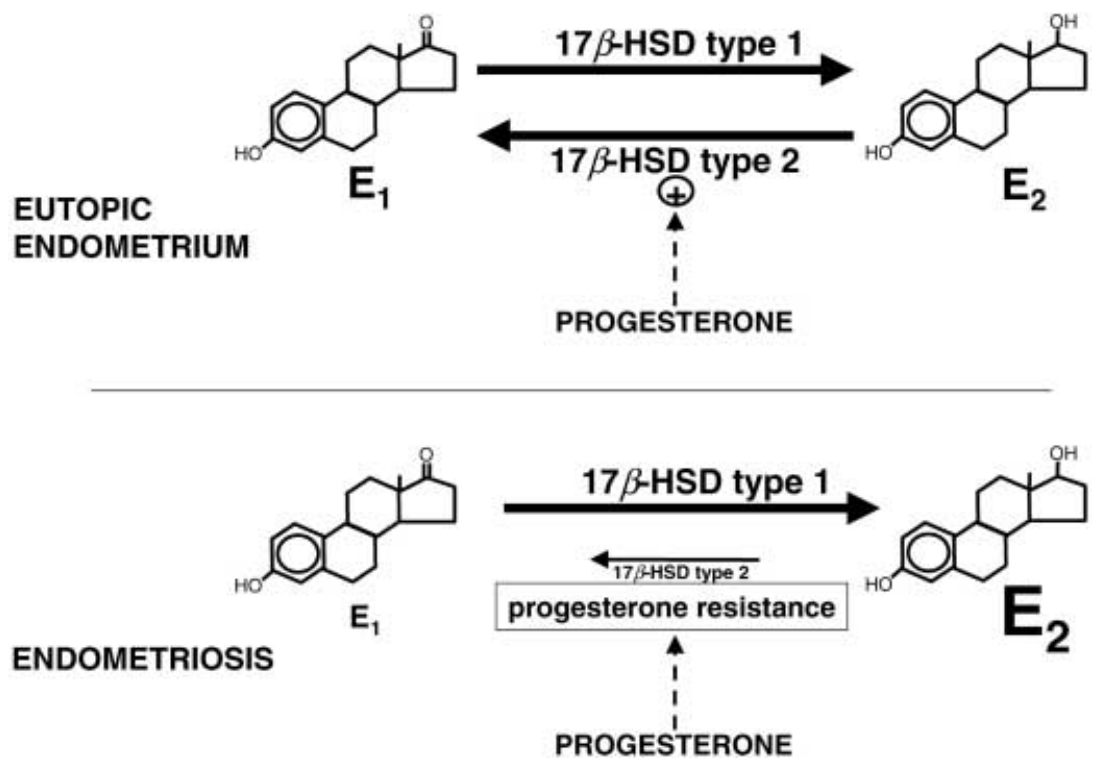

FIGURE 4. Defective inactivation of estradiol $\left(\mathrm{E}_{2}\right)$ in endometriosis: $\mathrm{E}_{2}$ reaches the endometriotic lesions via the blood stream. Additionally, estrone $\left(\mathrm{E}_{1}\right)$ is produced in the stromal cell via aberrant aromatase activity. Estrone is further reduced to $\mathrm{E}_{2}$ by $17 \beta$-HSD type 1 in the endometriotic tissue.

Estradiol is normally inactivated by conversion to $\mathrm{E}_{1}$ by $17 \beta-\mathrm{HSD}$ type 2 in epithelial cells of the eutopic endometrium in response to progesterone during the secretory phase. In endometriotic tissue, however, $\mathrm{E}_{2}$ is not metabolized owing to the lack of $17 \beta$-HSD type 2 , giving rise to increased local concentration of this potent estrogen. The absence of $17 \beta$-HSD type 2 expression in endometriosis despite high levels of progesterone during the secretory phase is indicative of selective progesterone resistance in this tissue.

inactivates estradiol by catalyzing its conversion to estrone in eutopic endometrial glandular cells during the luteal phase (Andersson \& Moghrabi 1997). Progesterone actually induces the activity of this enzyme in endometrial glandular cells in culture, making inactivation of estradiol to estrone one of the anti-estrogenic properties of progesterone (Satyaswaroop et al. 1982). The expression of $17 \beta$-HSD type 2 is absent from endometriotic glandular cells, as demonstrated in paired samples of eutopic endometrium and pelvic endometriosis obtained simultaneously during the luteal phase (Zeitoun et al. 1998). Consequently, this protective mechanism that lowers estradiol levels is lost in endometriotic tissue (Zeitoun et al. 1998). The aberrant expression of aromatase, the presence of $17 \beta$-HSD type 1 and the absence of $17 \beta$-HSD type 2 from endometriosis collectively give rise to elevated local levels of estradiol compared with eutopic endometrium. Additionally, 17 $\beta$-HSD type 2 deficiency may also be viewed as a defective action of progesterone, which fails to induce this enzyme in endometriotic tissue (Fig. 4).

\section{Rationale for using aromatase inhibitors to treat endometriosis}

Endometriosis is successfully suppressed by estrogen deprivation with $\mathrm{GnRH}$ analogs or the induction of surgical menopause. Control of pelvic pain with GnRH agonists is usually successful during and immediately after the treatment, whereas pain associated with endometriosis returns in up to $75 \%$ of these women (Henzl et al. 1988, Waller \& Shaw 1993). There may be multiple reasons for the failure of $\mathrm{GnRH}$ agonist treatment of endometriosis. One likely explanation is the presence of significant estradiol production that continues in the adipose tissue, skin and endometriotic implant per se during the GnRH agonist treatment. Therefore, blockage of aromatase activity in these extra-ovarian sites with an aromatase inhibitor may keep larger number of patients in remission for longer periods of time (Fig. 5). The most striking evidence for the significance of extra-ovarian estrogen production is the recurrence of endometriosis after successfully completed hysterectomy and bilateral salpingo-oophorectomy in a 


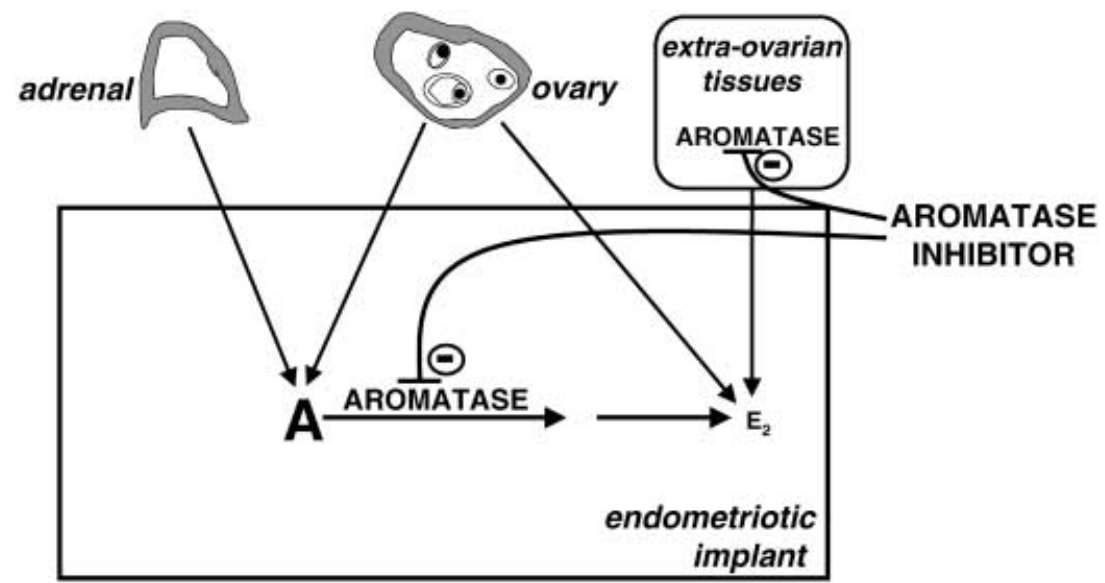

FIGURE 5. Sites of action of aromatase inhibitors to treat endometriosis. In cases resistant to treatment with $\mathrm{GnRH}$ agonists or in postmenopausal endometriosis, the use of aromatase inhibitors to block estrogen formation in the skin and adipose tissue as well as in endometriotic tissue may be critical in inhibiting the growth of endometriotic tissue. Recurrent endometriosis, especially after surgical removal of the ovaries, may represent lesions that are sensitive to extremely low levels of estradiol $\left(\mathrm{E}_{2}\right)$. Thus, suppression of $\mathrm{E}_{2}$ production in the extra-ovarian sites (adipose tissue/skin) and in endometriotic tissue may be mandatory for successful treatment of endometriosis.

number of women (Metzger et al. 1991, Takayama et al. 1998). Endometriotic tissue in one such aggressive case was found to express much higher levels of aromatase mRNA compared with premenopausal endometriosis (Takayama et al. 1998). We recently reported the treatment of a 57 -year-old overweight woman who had recurrence of severe endometriosis after hysterectomy and bilateral salpingo-oophorectomy. Two additional laparotomies were performed owing to persistent severe pelvic pain and bilateral ureteral obstruction leading to left renal atrophy and right hydronephrosis. Treatment with megestrol acetate was ineffective. A large $(3 \mathrm{~cm})$ vaginal endometriotic lesion contained unusually high levels of aromatase mRNA. The patient was given anastrozole (an aromatase inhibitor) for 9 months. Despite the addition of calcium and alendronate (a nonsteroidal inhibitor of bone resorption), bone density in the lumbar spine decreased by $6 \cdot 2 \%$. The occurrence of significant bone loss in this particular case should be studied further. Dramatic relief of the pain and regression of the vaginal endometriotic lesion were observed within the first month of treatment. At the same time, circulating estradiol levels were reduced to $50 \%$ of the baseline value. Markedly high pretreatment levels of aromatase mRNA in the endometriotic tissue became undetectable in a repeat biopsy 6 months later, and the lesion nearly disappeared after 9 months of therapy. Two potential mechanisms may have accounted for this strikingly successful result. Firstly, there was evidence of suppression of extra-ovarian (i.e. skin and adipose tissue) aromatase activity, giving rise to a significant decrease in serum estradiol level (Fig. 5). Secondly, unusually high levels of aromatase expression in the endometriotic lesion disappeared after treatment with the aromatase inhibitor, anastrozole (Fig. 5). Besides the expected direct inhibition of aromatase activity in endometriosis by anastrozole, the disappearance of aromatase mRNA expression in the lesion may be explicable by denial of estrogen that is known to stimulate local biosynthesis of $\mathrm{PGE}_{2}$, which, in turn, stimulates aromatase expression (Fig. 2).

In summary, the recently developed potent aromatase inhibitors are candidate drugs in the treatment of endometriosis that is resistant to standard regimens. In fact, the use of aromatase inhibitors may be the only available treatment for aggressive postmenopausal endometriosis. It remains to be seen whether aromatase inhibitors alone or together with present lines of therapy in premenopausal women will increase the pain-free interval and time to recurrence after discontinuation (Fig. 5). Studies are under way to address these questions. 


\section{SUMMARY}

The development and growth of endometriotic lesions are estrogen-dependent. The mechanisms and effectiveness of hormonal treatments for endometriosis should be re-evaluated in view of the new advances that increased our understanding of the body sites of estrogen production in a woman with endometriosis. In addition to ovarian secretion, estradiol is also produced in peripheral sites such as skin, adipose tissue and endometriotic lesions per se. We suggest that the intracrine and paracrine effects of estradiol produced in the target tissue amplify the estrogenic action of steroid hormones delivered via the circulation. Additionally, defective inactivation of estradiol in endometriosis in contrast to eutopic endometrium may further enhance this local effect. Aberrant aromatase activity and defective estradiol metabolism in endometriosis are consequences of specific molecular aberrations such as inappropriate expression of a stimulatory transcription factor or progesterone resistance in this tissue. The clinical relevance of these findings was recently exemplified by the successful treatment of a severe case of recurrent postmenopausal endometriosis with an aromatase inhibitor. Future treatment strategies may be designed to target the signal transduction for aromatase expression in endometriosis or to enhance progesterone action in this tissue.

\section{ACKNOWLEDGEMENTS}

We thank Margarita Guerrero and Dee Alexander for providing expert editorial assistance. This research work was supported, in part, by the NIH grants HD38691 and CA67167 (Serdar Bulun) and an AAOGF Fellowship Award (Khaled Zeitoun).

\section{REFERENCES}

Ackerman GE, Smith ME, Mendelson CR, MacDonald PC \& Simpson ER 1981 Aromatization of androstenedione by human adipose tissue stromal cells in monolayer culture. Fournal of Clinical Endocrinology and Metabolism 53 412-417.

Andersson S \& Moghrabi N 1997 Physiology and molecular genetics of $17 \beta$-hydroxysteroid dehydrogenases. Steroids $\mathbf{6 2}$ 143-147.

Bruner KL, Matrisian LM, Rodgers WH, Gorstein F \& Osteen KG 1997 Suppression of matrix metalloproteinases inhibits establishment of ectopic lesions by human endometrium in nude mice. Fournal of Clinical Investigation 99 2851-2857.

Bulun SE, Mahendroo MS \& Simpson ER 1993a Polymerase chain reaction amplification fails to detect aromatase cytochrome P450 transcripts in normal human endometrium or decidua. Fournal of Clinical Endocrinology and Metabolism 76 1458-1463.
Bulun SE, Price TM, Mahendroo MS, Aitken J \& Simpson ER 1993b A link between breast cancer and local estrogen biosynthesis suggested by quantification of breast adipose tissue aromatase cytochrome $\mathrm{P} 450$ transcripts using competitive polymerase chain reaction after reverse transcription. Fournal of Clinical Endocrinology and Metabolism 77 1622-1628.

Bulun SE, Simpson ER \& Word RA 1994 Expression of the CYP19 gene and its product aromatase cytochrome P450 in human leiomyoma tissues and cells in culture. Fournal of Clinical Endocrinology and Metabolism 78 736-743.

Halme J, White C, Kauma S, Estes J \& Haskill S 1988 Peritoneal macrophages from patients with endometriosis release growth factor activity in vitro. Fournal of Clinical Endocrinology and Metabolism 66 1044-1049.

Henzl MR, Corson SL, Moghissi K, Buttram VC, Berqvist C \& Jacobson J 1988 Administration of nasal nafarelin as compared with oral danazol for endometriosis. New England Fournal of Medicine 318 485-489.

Hill JA 1992 Immunology and endometriosis. Fertility and Sterility 58 262-264.

Huang JC, Dawood MY \& Wu KK 1996 Regulation of cyclooxygenase- 2 gene in cultured endometrial stromal cells by sex steroids. Proceedings of the American Society of Reproductive Medicine Meeting S5 (abstract).

Khorram O, Taylor RN, Ryan IP, Schall TJ \& Landers DV 1993 Peritoneal fluid concentrations of the cytokine RANTES correlate with the severity of endometriosis. American Fournal of Obstetrics and Gynecology 169 1545-1549.

Kjerulff KH, Erickson BA \& Langenberg PW 1996 Chronic gynecological conditions reported by US women: findings from the National Health Information Survey 1984 to 1992. American Fournal of Public Health 86 195-199.

MacDonald PC, Rombaut RP \& Siiteri PK 1967 Plasma precursors of estrogen I. Extent of conversion of plasma $\Delta^{4}$-androstenedione to estrone in normal males and non-pregnant normal, castrate and adrenalectomized females. Fournal of Clinical Endocrinology and Metabolism 27 1103-1111.

MacDonald PC, Edman CD, Hemsell DL, Porter J \& Siiteri PK 1978 Effect of obesity on conversion of plasma androstenedione to estrone in postmenopausal women with and without endometrial cancer. American Fournal of Obstetrics and Gynecology 130 448-455.

Metzger DA, Lessey BA, Soper JT, McCarty KS, Jr \& Haney AF 1991 Hormone-resistant endometriosis following total abdominal hysterectomy and bilateral salpingooophorectomy: correlation with histology and steroid receptor content. Obstetrics and Gynecology 78 946-950.

Michael MD, Kilgore MW, Morohashi KI \& Simpson ER 1995 Ad4 BP/SF-1 regulates cyclic AMP-induced transcription from the proximal promoter (PII) of the human aromatase P450 (CYP19) gene in the ovary. Fournal of Biological Chemistry 270 13561-13566.

Michael MD, Michael LF \& Simpson ER 1997 A CRE-like sequence that binds CREB and contributes to cAMPdependent regulation of the proximal promoter of the human aromatase P450 (CYP19) gene. Molecular and Cellular Endocrinology 134 147-156.

Noble LS, Simpson ER, Johns A \& Bulun SE 1996 Aromatase expression in endometriosis. Fournal of Clinical Endocrinology and Metabolism 81 174-179.

Noble LS, Takayama K, Putman JM, Johns DA, Hinshelwood MM, Agarwal VR, Zhao Y, Carr BR \& Bulun SE 1997 Prostaglandin $\mathrm{E}_{2}$ stimulates aromatase expression in endometriosis-derived stromal cells. Fournal of Clinical Endocrinology and Metabolism 82 600-606. 
Olive DL \& Schwartz LB 1993 Endometriosis. New England Fournal of Medicine 328 1759-1769.

Osteen KG, Bruner KL \& Sharpe-Timms KL 1996 Steroid and growth factor regulation of matrix metalloproteinase expression and endometriosis. Seminars in Reproductive Endocrinology 15 301-308.

Sampson JA 1927 Peritoneal endometriosis due to the menstrual dissemination of endometrial tissue into the peritoneal cavity. American Fournal of Obstetrics and Gynecology 14 422-425.

Satyaswaroop PG, Wartell DJ \& Mortel R 1982 Distribution of progesterone receptor, estradiol dehydrogenase, and $20 \alpha-$ dihydroprogesterone dehydrogenase activities in human endometrial glands and stroma: progestin induction of steroid dehydrogenase activities in vitro is restricted to the glandular epithelium. Endocrinology 111 743-749.

Sharpe-Timms KL, Penney LL, Zimmer RL, Wright JA, Zhang Y \& Surewicz K 1995 Partial purification and amino acid sequence analysis of endometriosis protein-II (ENDO-II) reveals homology with tissue inhibitor of metalloproteinases-1 (TIMP-1). Fournal of Clinical Endocrinology and Metabolism 80 3784-3787.

Simpson ER, Mahendroo MS, Means GD, Kilgore MW, Hinshelwood MM, Graham-Lorence S, Amarneh B, Ito Y, Fisher CR, Michael MD, Mendelson CR \& Bulun SE 1994 Aromatase cytochrome P450, the enzyme responsible for estrogen biosynthesis. Endocrine Reviews 15 342-355.
Takayama K, Zeitoun K, Gunby RT, Sasano H, Carr BR \& Bulun SE 1998 Treatment of severe postmenopausal endometriosis with an aromatase inhibitor. Fertility and Sterility 69 709-713.

Vessey MP, Villard-Mackintosh L \& Painter R 1993 Epidemiology of endometriosis in women attending family planning clinics. British Medical Fournal 306 182-184.

Waller KG \& Shaw RW 1993 Gonadotropin-releasing hormone analogues for the treatment of endometriosis: long-term follow-up. Fertility and Sterility 59 511-515.

Yue W, Wang JP, Hamilton CJ, Demers LM \& Santen RJ 1998 In situ aromatization enhances breast tumor estradiol levels and cellular proliferation. Cancer Research $\mathbf{5 8}$ 927-932.

Zeitoun K, Takayama K, Sasano H, Suzuki T, Moghrabi N, Andersson S, Johns A, Meng L, Putman M, Carr B \& Bulun SE 1998 Deficient 17ß-hydroxysteroid dehydrogenase type 2 expression in endometriosis: failure to metabolize estradiol-17 $\beta$. Fournal of Clinical Endocrinology and Metabolism 83 4474-4480.

Zeitoun K, Takayama K, Michael MD \& Bulun SE 1999 Stimulation of aromatase $\mathrm{P} 450$ promoter (II) activity in endometriosis and its inhibition in endometrium are regulated by competitive binding of SF-1 and COUP-TF to the same cis-acting element. Molecular Endocrinology 13 239-253.

RECEIVED 17 December 1999 